\title{
A RELAÇÃO DIALÉTICA ENTRE SUBJETIVIDADE E OBJETIVIDADE: MATERIALISMO HISTÓRICO E PSICOLOGIA HISTÓRICO-CULTURAL ${ }^{1}$
}

\author{
LA RELACIÓN DIALÉCTICA ENTRE SUBJETIVIDAD Y OBJETIVIDAD: \\ MATERIALISMO HISTÓRICO Y PSICOLOGÍA HISTÓRICO-CULTURAL
}

\section{THE DIALECTICAL RELATIONSHIP BETWEEN SUBJECTIVITY AND OBJECTIVITY: HISTORICAL MATERIALISM AND HISTORICAL-CULTURAL PSYCHOLOGY}

\author{
DOI: http://dx.doi.org/10.9771/gmed.v11i1.27465
}

\author{
Camila Azevedo Souza²
}

Como o ano de 2018 está marcado pelo bicentenário de Karl Marx e pelos 170 anos de Manifesto Comunista, ainda configura-se um momento notadamente importante para reafirmar a compreensão de que é a vida que determina a consciência, haja vista a relação dialética entre produção intelectual e produção material (MARX \& ENGELS, 2005), contribuindo para o enfrentamento e a superação, entre outros desafios, das influências economicistas e positivistas de um "marxismo vulgar". Considerando que o interesse de Marx "não incidia sobre um abstrato 'como conhecer', mas sobre 'como conhecer um objeto real e determinado"' (NETTO, 2011, p.27), cabe destacar a necessária indissociabilidade entre sujeito e objeto enquanto orientação fundamental para manter o rigor teóricometodológico nas análises alicerçadas no materialismo histórico, compreendendo a relação dialética que imbrica subjetividade e objetividade; particularidade e totalidade; singularidade e universalidade; individualidade e coletividade.

Objeto da presente resenha, a obra "Periodização histórico-cultural do desenvolvimento psíquico: do nascimento à velhice", publicada em 2016, constitui uma importante contribuição nessa direção, pois sua principal fundamentação é a compreensão de que o desenvolvimento humano é cultural, histórico e socialmente condicionado pela totalidade indivíduo/realidade social, ou seja, pelo entrelaçamento dialético das dimensões biológica e cultural.

O livro é prefaciado por Marta Shuare, que destaca sua importância para psicólogos e pedagogos avançarem na compreensão do desenvolvimento humano com base na teoria histórico-cultural, e organizado por Lígia Márcia Martins, Angelo Antonio Abrantes e Marilda Gonçalves Facci, que ressaltam sua relevância por sistematizar uma análise da formação do psiquismo sob a perspectiva do materialismo histórico-dialético, fundamentando-se principalmente em Vigotski, Leontiev e Elkonin, com ênfase para 
as contradições do movimento histórico da luta de classes das formações sociais capitalistas e para as atividades que possibilitam saltos qualitativos no modo de ser do indivíduo.

Considerando o caráter ainda pouco explorado que marca a temática da periodização históricocultural do desenvolvimento psíquico, os organizadores evidenciam, também, a articulação entre psicologia histórico-cultural e pedagogia histórico-crítica, partindo do pressuposto do ensino como esteira do desenvolvimento e da escola como locus privilegiado para sua promoção.

Estruturado enquanto uma coletânea de textos, mas mantendo uma unidade conceitual entre os capítulos, o livro abrange seis partes: Fundamentos teórico-metodológicos; Primeira infância; Infância; Adolescência; Idade adulta e velhice; Épocas do desenvolvimento e a educação escolar.

A primeira parte, sobre a fundamentação teórico-metodológica, é composta pelo capítulo 1, "Psicologia histórico-cultural, pedagogia histórico-crítica e desenvolvimento humano"; pelo capítulo 2, "A periodização do desenvolvimento psíquico: atividade dominante e a formação das funções psíquicas superiores"; e pelo capítulo 3, "A teoria histórico-cultural da periodização do desenvolvimento psíquico como expressão do método materialista dialético".

O capítulo 1, de autoria de Lígia Márcia Martins, aborda a questão do desenvolvimento humano articulando as contribuições da psicologia histórico-cultural e da pedagogia histórico-crítica sob três perspectivas: da promoção do desenvolvimento, considerando a relação entre a atividade do trabalho e o conceito de signo cultural (estímulo de segunda ordem), com ênfase no processo de transformação das funções psíquicas elementares em funções psíquicas superiores; da formação dos “verdadeiros” conceitos, considerando a interdependência entre desenvolvimento do pensamento abstrato e formação de conceitos (científicos, clássicos), com ênfase no papel da educação escolar de disponibilizar objetivações humano-genéricas à apropriação dos indivíduos particulares e promover o desenvolvimento omnilateral dos sujeitos; e da organização do ensino, considerando a defesa da prática pedagógica voltada para o máximo desenvolvimento das pessoas, com ênfase no papel da catarse (saltos qualitativos) para a superação por incorporação que caracteriza a periodização do desenvolvimento.

No capítulo 2, Silvana Calvo Tuleski e Nadia Mara Eidt trabalham a questão da periodização do desenvolvimento psíquico a partir da compreensão da lei da internalização como lei geral do desenvolvimento das funções psíquicas superiores ou culturais, evidenciando a unidade dialética fabrico de instrumentos/criação de signos que caracteriza as relações sociais de produção, com destaque para dois conceitos centrais: o de atividade dominante (atividade-guia), partindo da relação entre a atividade humana (intencional e consciente) e a formação das funções psíquicas mais complexas (culturalmente formadas) para ressaltar o caráter dinâmico dos processos psíquicos que marcam cada período do desenvolvimento; e o de neoformação (sínteses complexas), considerando a unidade biológico-social do desenvolvimento para elucidar o movimento de mobilização de funções psíquicas ainda não completamente desenvolvidas para atender às exigências da situação social de desenvolvimento.

O capítulo 3, cuja autora é Juliana Campregher Pasqualini, analisa a teoria da periodização do desenvolvimento psíquico da Escola de Vigotski com base no método materialista dialético, partindo da compreensão da necessária captação da lógica interna do desenvolvimento psíquico para abordar os 
seguintes princípios metodológicos: a atividade humana sob a perspectiva da totalidade e historicidade explica o psiquismo individual; o desenvolvimento psíquico é fruto de um movimento que combina períodos estáveis de mudanças graduais e períodos críticos de saltos qualitativos, bem como é determinado pela contradição entre as capacidades do indivíduo e seu modo de vida; a transição entre períodos do desenvolvimento ocorre por um processo de superação dialética em que as atividades são incorporadas, requalificadas e realocadas; os períodos ou idades constituem, a partir da unidade dialética todo-parte, formações globais e dinâmicas que determinam o papel e o peso específico de cada linha parcial de desenvolvimento; e as formas mais desenvolvidas da atividade humana (apropriações cada vez mais ricas e complexas da cultura humana), a partir da unidade dialética quantidade-qualidade, são referência para a análise do psiquismo.

Alicerçados nas contribuições tecidas nessa primeira parte, os demais capítulos seguem com a análise das especificidades de cada período do desenvolvimento considerando a unidade sujeito-objeto na relação dialética entre o biológico (idade cronológica) e o cultural (condições concretas de vida).

A segunda parte, sobre a época da Primeira infância, é composta pelo capítulo 4, "O primeiro ano de vida, vida uterina, transição pós-natal e atividade de comunicação emocional direta com o adulto"; e pelo capítulo 5, "Primeira infância: educação e cuidados para o desenvolvimento humano".

O capítulo 4, de autoria de Simone Cheroglu e Giselle Modé Magalhães, aborda a unidade dialeticamente contraditória entre natureza e cultura para evidenciar que o desenvolvimento do bebê sofre influência direta das condições de vida da gestante, abordando os três períodos do desenvolvimento no período do primeiro ano de vida: período uterino (atividade reflexa e formação de pré-condições para sistemas funcionais complexos); período pós-natal (atividade nervosa superior e transformação gradativa da passividade em interesse); e período da atividade de comunicação emocional direta, a primeira atividade-guia do desenvolvimento do bebê (centralidade da relação com o adulto social e caráter exploratório das ações iniciais com objetos).

No capítulo 5, Marta Chaves e Adriana de Fátima Franco, considerando o entrelaçamento entre desenvolvimento e condições objetivas de vida, analisam o desenvolvimento do psiquismo no período da primeira infância (de 1 ano a 3 anos), cuja atividade-guia é a objetal manipulatória, defendendo a organização da rotina (tempo e espaço) para instrumentalizar intervenções educativas capazes de disponibilizar as máximas elaborações humanas às crianças. Nessa direção, as autoras evidenciam o declínio da atividade de comunicação emocional direta e o surgimento da atividade objetal manipulatória (centralidade da relação com o objeto social e percepção visual direta), apontando um salto qualitativo a partir do entrecruzamento entre linguagem e pensamento, com destaque para o pensamento sincrético e a atividade de quase jogo.

A terceira parte, sobre a época da Infância, é composta pelo capítulo 6, "Idade pré-escolar (3-6 anos) e a educação infantil: a brincadeira de papéis sociais e o ensino sistematizado"; pelo capítulo 7, "A transição da educação infantil para o ensino fundamental: dos jogos de papéis sociais à atividade de estudo"; e pelo capítulo 8, "Idade escolar e atividade de estudo: educação, ensino e apropriação dos sistemas conceituais". 
O capítulo 6, cuja autora é Lucinéia Maria Lazaretti, analisa o período da idade pré-escolar (de 3 anos a 6 anos), marcado pela transição da atividade objetal manipulatória para a atividade da brincadeira de papéis sociais, atividade-guia caracterizada pelo interesse da criança no significado social das ações com objetos (centralidade da relação com o adulto social e autocontrole da conduta). Nesse sentido, a autora evidencia que o conteúdo da brincadeira é de origem social, histórica e cultural, precisando da intervenção direta do adulto (modelo de ação) para avançar na complexificação das funções psíquicas, com destaque para a atividade produtiva como linha acessória do desenvolvimento.

No capítulo 7, Josy Cristine Martins e Marilda Gonçalves Dias Facci analisam as mudanças psíquicas na passagem do período da idade pré-escolar para o período da idade escolar, referente à transição da educação infantil para o ensino fundamental, sob a perspectiva de três dimensões: da crise dos 7 anos, marcada pelo início da diferenciação entre o aspecto interior e exterior da personalidade, bem como da atribuição de significado às vivências e da distinção dos sentimentos; das atividades dominantes de cada período (a de jogos de papéis na idade pré-escolar e a de estudo na idade escolar), destacando que a criança começa a aprender por meio das brincadeiras e que a entrada na escola promove mudanças decisivas no desenvolvimento psíquico da criança; e da preparação das crianças para a atividade de estudo, defendendo a definição dos conteúdos, sob a perspectiva da função social da escola de socializar os conhecimentos historicamente elaborados desde a educação infantil.

O capítulo 8, de autoria de Flávia da Silva Ferreira Asbahr, aborda o período da idade escolar (de 6-7 anos a 10 anos), cuja atividade-guia é o estudo compreendido como atividade humana representada nas formas desenvolvidas de consciência social (centralidade do conhecimento como objeto social e formação do pensamento teórico como neoformação psicológica essencial ao processo de humanização), caracterizando as especificidades dessa atividade em sua formação, que objetiva os motivos para o estudo; em seu conteúdo, fundamentado nos conhecimentos teóricos; e em sua estrutura, voltada para o procedimento de ascensão do abstrato ao concreto. Além disso, a autora destaca que a formação do pensamento teórico (papel central da palavra) deve ser a principal finalidade do ensino escolar, destacando que a atividade em comum e coletiva entre estudantes e professores é essencial para a organização do ensino.

A quarta parte, sobre a época da Adolescência, é composta pelo capítulo 9, "A adolescência inicial: comunicação íntima pessoal, atividade de estudo e formação de conceitos”; e pelo capítulo 10 , "Adolescência: trabalho educação e a formação omnilateral".

No capítulo 9, Ricardo Eleutério dos Anjos e Newton Duarte, considerando a adolescência como um fenômeno produzido pelo movimento histórico das sociedades de classes, analisam o período da adolescência (de 11-12 anos a 15 anos ${ }^{3}$ ), cuja atividade-guia é a comunicação íntima pessoal (centralidade da relação com a coletividade, autoconsciência e adulto como referência) em relação dialética com a atividade de estudo (preparação para futura atuação profissional), com destaque para a formação do pensamento por conceitos e a consequente estruturação da personalidade e da concepção de mundo como um salto qualitativo no desenvolvimento psíquico do adolescente. Nessa direção, haja vista a urgência da superação das pedagogias do "aprender a aprender", os autores asseveram que a educação escolar tem 
papel fundamental no processo de formação do pensamento conceitual a partir transmissão da cultura construída historicamente pelos homens; ou seja, trata-se de uma educação escolar que cria nos alunos a necessidade de apropriação das objetivações genéricas mais elaboradas (conhecimentos mais desenvolvidos, produções mais elaboradas), consolidando-se como mediação entre os conceitos cotidianos e os conceitos científicos.

O capítulo 10, de Zaira F. de Rezende Gonzales Leal e Gisele Cristina Mascagna, tece uma análise sobre a adolescência, compreendida como uma construção histórica em relação com a cultura e a sociedade, evidenciando um período marcado pela formação do pensamento por conceitos que repercute na edificação de uma concepção de mundo e na preparação para a entrada na vida adulta e no mundo do trabalho, com destaque tanto para as contradições da organização social capitalista, que conduz a uma degradação da personalidade humana, como para a contribuição de uma educação escolar fundamentada no trabalho como princípio educativo e comprometida com a emancipação humana, que permite o desenvolvimento pleno dos indivíduos sob a perspectiva da omnilateralidade.

A quinta parte, sobre as épocas da Idade adulta e da Velhice, é composta pelo capítulo 11, "Idade adulta e o desenvolvimento psíquico na sociedade de classes: juventude e trabalho"; pelo capítulo 12, "Idade adulta, trabalho e desenvolvimento psíquico: a maturidade em tempos de reestruturação produtiva"; e pelo capítulo 13, "A velhice sob o enfoque da psicologia histórico-cultural”.

No capítulo 11, Angelo Antonio Abrantes e Larissa Bulhões abordam a juventude como o período inicial da vida adulta (de 18 anos a 24 anos), que está marcado pela unidade contraditória entre atividade de estudo profissionalizante e atividade produtiva, cuja predominância de uma ou outra atividade é determinada pela posição do jovem nos meios de produção. Nessa direção, partindo do pressuposto de que os aspectos biológicos existem e subordinam-se às leis histórico-sociais no movimento histórico da luta de classes, os autores tecem três perspectivas de análise: definição de juventude a partir da relação com o trabalho (autonomia e atividade socialmente produtiva), com destaque para o desenvolvimento do jovem em relação tanto às formas de alienação como às possibilidades de uma práxis consciente no contexto de uma existência determinada pela realidade do desemprego estrutural e do trabalho precário; elucidação da contradição central entre capital e trabalho e seus desdobramentos para a subsunção do jovem da classe trabalhadora a partir de um processo de conformação educativa (parco acesso aos conceitos científicos), com destaque para a correlação entre a apropriação das objetivações humanogenéricas e o desenvolvimento da consciência; e compreensão do jovem adulto em seu vir a ser, com destaque para a produção ativa de um projeto de existência considerando que um projeto de vida é ao mesmo tempo um projeto de sociedade.

O capítulo 12, de Saulo Rodrigues e Lígia Márcia Martins, aborda o período de maturidade na vida adulta, cuja atividade-guia é o trabalho enquanto produção social, partindo da fundamentação no método inverso de Vigotski para evidenciar a unidade contraditória entre aquilo que o sujeito é e aquilo que ele pode vir a ser (máximas possibilidades do gênero humano), com destaque para a intencionalidade como uma das características centrais da atividade humana. Nesse sentido, os autores avançam com a análise de três questões centrais: a dupla dimensão do trabalho, que compreende o trabalho como 
humanização (relação dialética entre apropriação-objetivação-exteriorização) e, ao mesmo tempo, como alienação (deformação da personalidade humana); a alienação em tempos de reestruturação produtiva, que consolida um "fetichismo generalizado" que influi decisivamente na consciência de explorados e exploradores (lógica da multifuncionalidade alienada do trabalhador desespecializado sob o amparo do “aprender a aprender" e consumo como única possibilidade de afirmação da pessoalidade); e luta pela superação das relações de alienação, que identifica-se com a luta pela vivência da atividade-guia na idade adulta sob a perspectiva da formação de uma possível e almejada personalidade livre e universal.

O capítulo 13, de Clayton Washington dos Reis e Marilda Gonçalves Dias Facci, evidencia a velhice como um período de desenvolvimento influenciado pelas condições históricas da humanidade, organizando a análise em três partes que abrangem: o resgate histórico do papel da velhice, com destaque para a oscilação entre uma referência negativa (imagem do fim, da morte, do mal e da perda) e uma referência positiva (sabedoria, conhecimento e respeito); as produções científicas marcadas pela tendência do paradigma biopsicossocial, com destaque para a desconsideração do processo de construção social da velhice; e a caracterização do trabalho como atividade dominante nessa fase da vida a partir da abordagem histórico-cultural, com destaque para a passagem da vida adulta para a velhice como um momento de crise marcado pela ruptura com o mundo formal do trabalho, uma vez que o trabalho (atividade dominante da vida adulta) não deixa de fazer parte da vida do idoso, ocorrendo uma mudança na sua relação com essa atividade.

A sexta parte, sobre as contribuições para a educação escolar, é composta pelo capítulo 14, "A periodização histórico-cultural do desenvolvimento na educação especial: o problema da idade"; e pelo capítulo 15, "Contribuições da periodização histórico-cultural do desenvolvimento para o trabalho pedagógico histórico-crítico".

No capítulo 14, Sonia Mari Shima Barroco e Nilza Sanches Tessaro Leonardo analisam a educação especial a partir da psicologia histórico-cultural (formação social do psiquismo e tese básica de Vigotski para a defectologia) e defendem o acesso dos sujeitos com deficiência ou transtornos globais do desenvolvimento a estágios superiores de desenvolvimento psíquico a partir do enraizamento na cultura, ressaltando quatro questões: o desenvolvimento humano normal e especial é histórico-social; o ser humano é síntese das relações sociais, com destaque para a mediação do comportamento humano por instrumentos e signos; a mediação de estratégias culturais permite a compensação social da condição diferenciada de desenvolvimento; e a construção de uma educação especial revolucionária está baseada no envolvimento com o trabalho socialmente útil, com destaque para a abordagem da periodização do desenvolvimento e da idade-problema a partir de um diagnóstico normativo da idade (determinação dos dois níveis de desenvolvimento - o real/maduro e o próximo/imaturo). Por fim, as autoras destacam a perspectiva vigotskiana tanto de crítica a uma pedagogia dita especial (fraca e destinada aos fracos) como de defesa a uma escola auxiliar (forte para quem for considerado fraco).

O capítulo 15, de Ana Carolina Galvão Marsiglia e Maria Cláudia da Silva Saccomani, tece uma análise sobre a relação entre periodização do desenvolvimento e trabalho pedagógico com base na psicologia histórico-cultural e na pedagogia histórico-crítica, evidenciando que o máximo desenvolvimento 
psíquico exige ações educativas intencionais que viabilizem a apropriação da cultura. Nesse sentido, a partir da compreensão da interdependência entre ensino, aprendizagem e desenvolvimento, as autoras enfatizam o destinatário do processo educativo, haja vista a tríade conteúdo-forma-destinatário, considerando a importância de compreender o aluno concreto (e não o aluno empírico em seus interesses e necessidades imediatas), com destaque para um ensino que desenvolve ações alicerçadas na relação dialética entre atividade-guia (nível de desenvolvimento real) e linhas acessórias de desenvolvimento (área de desenvolvimento iminente). Por fim, destaca-se a categorização de conteúdos de formação operacional (conhecimentos científicos que orientam o trabalho do professor e chegam indiretamente) e formação teórica (conhecimentos científicos que são convertidos em saberes escolares e ensinados diretamente) para caracterizar o trabalho educativo a ser desenvolvido em cada período de desenvolvimento, asseverando que não é a idade cronológica que garante o pensamento conceitual, mas sim o processo educativo sistematizado.

Sob a perspectiva de enriquecer o debate e contribuir com o processo de construção coletiva do conhecimento, haja vista a compreensão nuclear de cultura da obra resenhada enfatizar ora a perspectiva da apropriação e objetivação da cultura humana (instrumentos, objetos e signos culturais) e ora a perspectiva da dimensão cultural (condições sociais) em relação dialética com a dimensão biológica, considero que o conjunto de análises dessa obra pode constituir um importante ponto de partida para inspirar futuros estudos adensados, principalmente, com as concepções de cultura e de educação dos pensadores marxistas Gramsci, Thompson e Williams, as quais estão fundamentadas na perspectiva de classe como categoria histórica e relacional.

Duas contribuições são importantes para impulsionar esse possível diálogo. Por um lado, Angela Martins e Lúcia Neves evidenciam que as formulações de Gramsci sobre cultura e política contribuíram "para a construção do materialismo humanista de Thompson e para o materialismo cultural de Williams", que concebem "a cultura no sentido amplo, como modo de vida, como modo de luta e, também, no sentido restrito, como produção intelectual e artística" (MARTINS \& NEVES, 2013, p.350). Tratam-se, portanto, de contribuições que "nos ajudam a superar a ideia, ainda tão presente no senso comum das sociedades contemporâneas, que relaciona cultura à erudição", uma vez que "a experiência vivida deve ser sempre o ponto de partida da ação pedagógica, e o trabalho pedagógico, em sentido amplo e em sentido estrito, consiste em encontrar o justo equilíbrio entre o conhecimento produzido pela humanidade e a experiência vivida pelos estudantes" (MARTINS \& NEVES, 2013, p.356-357).

Por outro lado, Sonia Rummert aborda a relação entre a educação de jovens e adultos trabalhadores e a produção social da existência a partir da concepção gramsciana da escola (unitária) ligada à vida e da compreensão thompsiana da dialética necessária entre educação e experiência, cuja análise é adensada pelas proposições de Saviani, Vieira Pinto e Vigotski, considerando tais contribuições como "bases teórico-metodológicas para a educação comprometida com a classe trabalhadora" (RUMMERT, 2014, p.85). Tal perspectiva de análise, articulada com as sistematizações já desenvolvidas com base na pedagogia histórico-crítica e na psicologia histórico-cultural, tem a potencialidade de contribuir com 
subsídios específicos para a construção coletiva de uma proposta teórico-prática para a educação de jovens e adultos trabalhadores alicerçada em uma pedagogia de inspiração marxista.

\section{Referências}

MARTINS, Angela Maria Souza \& NEVES, Lúcia Maria Wanderley. Materialismo histórico, cultura e educação: Gramsci, Thompson e Williams. Revista HISTEDBR On-line, Campinas, nº 51, p. 341-359, jun.2013.

MARX, Karl \& ENGELS, Friedrich. Manifesto Comunista. Organização e introdução: Osvaldo Coggiola. São Paulo: Boitempo Editorial, 2005.

NETTT, José Paulo. Introdução ao estudo do método de Marx. São Paulo: Expressão Popular, 2011.

RUMMERT, Sonia Maria. Trabalho, educação e experiência na formação de jovens e adultos trabalhadores. In: ALVES, Natália; RUMMERT, Sonia Maria e MARQUES, Marcelo. Educação e Formação de Jovens e Adultos em Portugal e no Brasil: Políticas, Práticas e Atores. Lisboa: Instituto de Educação da Universidade de Lisboa, 2014, p.73-88.

\section{Notas:}

${ }^{1}$ MARTINS, Lígia Márcia; ABRANTES, Angelo Antonio \& FACCI, Marilda Gonçalves (Org.). Periodização histórico-cultural do desenvolvimento psiquico: do nascimento à velhice. Campinas, SP: Autores Associados, 2016.

2 Formada em Pedagogia pela Universidade Federal de Juiz de Fora (UFJF), Mestre e Doutoranda em Educação pela Universidade Federal Fluminense (UFF). Vinculada ao Núcleo de Estudos, Documentação e Dados sobre Trabalho e Educação (NEDDATE-UFF) e ao Grupo de Pesquisa EJA Trabalhadores. Email: camilaazevedosouza@yahoo.com.br

3 Cabe destacar que o capítulo 15 aborda a época da adolescência caracterizando-a em dois períodos: o a da adolescência inicial (de 10 anos a 14 anos) e o da adolescência (de 14 anos a 17 anos). 